\title{
A CLASS OF SYMMETRIC FUNCTIONS FOR MULTIPLICATIVELY CONVEX FUNCTION
}

\author{
KAIZHONG GUAN
}

Abstract. A new symmetric function, which generalizes Hamy symmetric function, is defined. Its properties, including Schur-geometric convexity, are investigated. Some analytic inequalities are also established.

Mathematics subject classification (2000): 26A51, 26D15, 0E05. convexity.

Key words and phrases: Multiplicatively convex function; Hamy symmetric function; Schur-geometric

\section{REFERENCES}

[1] Constantin P. Niculescu, Convexity according to the geometric mean, Math. Inequal. Appl., 3, (2) (2000), 155-167.

[2] A. W. MARShall AND I. OlkIn, Inequalities: Theory of Majorization and Its Applications, Academic Press, New Yok, 1979.

[3] G. H. HARDY, J. E. LitTLEWOOD, AND D. PóLYA, Some simple inequalities satisfied by convex functions, Messenger Math., 58, (1929),145-152.

[4] X. M. Zhang, Geometrically-convex Functions (in Chinese), Anhui University Press, Hefei, 2004.

[5] T. HARA, M. UCHIYAMA AND S. TAKAHASI, A refinement of various mean inequalities, J. of Inequal. Appl., 2,(1998), 387-395.

[6] H. T. KU, M. C. KU AND X. M. ZHANG, Inequalities for symmetric means, symmetric harmonic means and theirs applications, Bull. Austral. Math. Soc., 56,(1997), 409-420.

[7] K. Z. Guan, The Hamy symmetric function and its generalization, Math. Inequal. Appl., 9, (4) (2006), 797-805.

[8] P. S. Bullen, Handbook of Means and Their Inequalities, Kluwer Academic Publishers, Dordrecht, 2003.

[9] E. F. BeCKENBACH AND R. Bellman, Inequalities, Springer-Verlag, Berlin, 1961. 